Francois J. F. Jacobs* and Alice Brink

\title{
Crystal structure of fac-tricarbonyl-(nitrato- ${ }^{1} O$ )- bis(pyridine- $\mathrm{KN}$ )-rhenium, $\mathrm{C}_{13} \mathrm{H}_{10} \mathrm{O}_{6} \mathrm{~N}_{3} \mathrm{Re}$
}

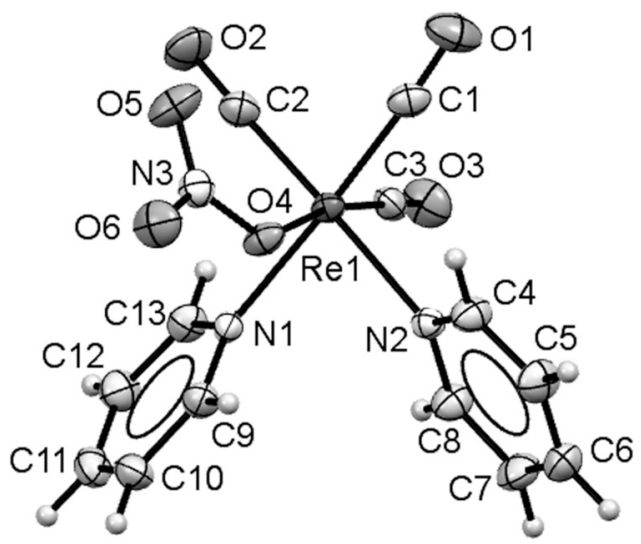

https://doi.org/10.1515/ncrs-2020-0475

Received September 15, 2020; accepted October 13, 2020; published online November 19, 2020

\section{Abstract}

$\mathrm{C}_{13} \mathrm{H}_{10} \mathrm{O}_{6} \mathrm{~N}_{3} \mathrm{Re}$, monoclinic, $P 2_{1} / c$ (no. 14), $a=7.9325(9) \AA$, $b=13.811(2) \AA, \quad c=13.458(2) \AA, \quad \beta=92.637(4)^{\circ}$, $V=1472.83(4) \AA^{3}, Z=4, R_{\mathrm{gt}}(F)=0.0249, w R_{\mathrm{ref}}\left(F^{2}\right)=0.0568$, $T=100(2) \mathrm{K}$.

\section{CCDC no.: 2024932}

The molecular structure is shown in the Figure. Table 1 contains crystallographic data, and Table 2 contains the list of the atoms including atomic coordinates and displacement parameters.

\section{Source of material}

The title compound was crystallised from the intermediate fac- $\left[\operatorname{Re}^{\mathrm{I}}(\mathrm{CO})_{3}\left(\mathrm{HOCH}_{3}\right)_{3}\right] \mathrm{NO}_{3}$ in the presence of excess pyridine during the reaction indicated in literature [6]. The title compound was crystallized from the methanol filtrate in high purity. IR (ATR, $\mathrm{cm}^{-1}$ ): v(CO) 2018, 1897, 1882.

*Corresponding author: Francois J. F. Jacobs, Department of Chemistry, University of the Free State, P. O. Box 339, Bloemfontein, 9300, South Africa, E-mail: fjfjacobs7@gmail.com. https://orcid.org/ 0000-0003-4965-9781

Alice Brink, Department of Chemistry, University of the Free State, P. 0. Box 339, Bloemfontein, 9300, South Africa
Table 1: Data collection and handling.

\begin{tabular}{ll}
\hline Crystal: & Yellow cuboid \\
Size: & $0.12 \times 0.10 \times 0.09 \mathrm{~mm}$ \\
Wavelength: & Mo $K \alpha$ radiation $(0.71073 \AA)$ \\
$\mu:$ & $8.29 \mathrm{~mm}^{-1}$ \\
Diffractometer, scan mode: & Bruker D8 Quest Photon II, $\varphi$ and $\omega$ \\
$\theta_{\max }$, completeness: & $28.0^{\circ},>99 \%$ \\
$N(h k l)_{\text {measured, }}$ & $22423,3551,0.059$ \\
$N(h k l)_{\text {unique }}, R_{\text {int }}:$ & \\
Criterion for $I_{\text {obs }}, N(h k l)_{\text {gt }}:$ & $I_{\text {obs }}>2 \sigma\left(I_{\text {obs }}\right), 3221$ \\
$N(\text { param })_{\text {refined }}:$ & 208 \\
Programs: & Bruker [1], Mercury [2], Olex2 [3], \\
& SHELX [4, 5] \\
\hline
\end{tabular}

Table 2: Fractional atomic coordinates and isotropic or equivalent isotropic displacement parameters $\left(\AA^{2}\right)$.

\begin{tabular}{lrrrr}
\hline Atom & $\boldsymbol{x}$ & $\boldsymbol{y}$ & $\boldsymbol{z}$ & $\boldsymbol{U}_{\text {iso }}{ }^{*} \boldsymbol{U}_{\text {eq }}$ \\
\hline Re1 & $0.82346(2)$ & $0.60717(2)$ & $0.23467(2)$ & $0.01993(6)$ \\
O1 & $0.9999(4)$ & $0.7809(2)$ & $0.3355(3)$ & $0.0446(8)$ \\
O2 & $0.8813(4)$ & $0.7187(3)$ & $0.0431(2)$ & $0.0434(8)$ \\
O3 & $1.1633(4)$ & $0.5106(2)$ & $0.2097(3)$ & $0.0400(8)$ \\
O4 & $0.5694(3)$ & $0.65047(19)$ & $0.2630(2)$ & $0.0259(6)$ \\
O5 & $0.5590(4)$ & $0.7776(2)$ & $0.1658(2)$ & $0.0408(8)$ \\
O6 & $0.3334(4)$ & $0.7254(3)$ & $0.2329(3)$ & $0.0407(8)$ \\
N1 & $0.6918(4)$ & $0.4887(2)$ & $0.1523(2)$ & $0.0203(6)$ \\
N2 & $0.7788(4)$ & $0.5261(2)$ & $0.3727(2)$ & $0.0204(6)$ \\
N3 & $0.4848(4)$ & $0.7193(2)$ & $0.2186(3)$ & $0.0266(7)$ \\
C1 & $0.9329(5)$ & $0.7147(3)$ & $0.3013(3)$ & $0.0279(9)$ \\
C2 & $0.8561(5)$ & $0.6769(3)$ & $0.1148(3)$ & $0.0297(9)$ \\
C3 & $1.0357(5)$ & $0.5481(3)$ & $0.2198(3)$ & $0.0249(8)$ \\
C4 & $0.7270(6)$ & $0.5722(3)$ & $0.4530(3)$ & $0.0285(9)$ \\
H4 & 0.703536 & 0.639508 & 0.448206 & $0.034^{*}$ \\
C5 & $0.7061(6)$ & $0.5265(3)$ & $0.5426(3)$ & $0.0349(10)$ \\
H5 & 0.669290 & 0.562043 & 0.598025 & $0.042^{*}$ \\
C6 & $0.7389(6)$ & $0.4287(3)$ & $0.5512(3)$ & $0.0315(9)$ \\
H6 & 0.725332 & 0.395332 & 0.612100 & $0.038^{*}$ \\
C7 & $0.7924(6)$ & $0.3809(3)$ & $0.4680(4)$ & $0.0353(10)$ \\
H7 & 0.816355 & 0.313577 & 0.471064 & $0.042^{*}$ \\
C8 & $0.8107(5)$ & $0.4309(3)$ & $0.3811(3)$ & $0.0285(9)$ \\
H8 & 0.847268 & 0.396869 & 0.324635 & $0.034^{*}$ \\
C9 & $0.5407(5)$ & $0.4549(3)$ & $0.1772(3)$ & $0.0275(8)$ \\
H9 & 0.491407 & 0.480334 & 0.234745 & $0.033^{*}$ \\
C10 & $0.4537(6)$ & $0.3844(3)$ & $0.1223(3)$ & $0.0310(9)$ \\
H10 & 0.347529 & 0.361627 & 0.142356 & $0.037^{*}$ \\
C11 & $0.5234(6)$ & $0.3479(3)$ & $0.0381(3)$ & $0.0325(10)$ \\
H11 & 0.466412 & 0.299450 & -0.000679 & $0.039^{*}$ \\
C12 & $0.6782(6)$ & $0.3833(3)$ & $0.0111(3)$ & $0.0330(10)$ \\
& & & &
\end{tabular}


Table 2: (continued)

\begin{tabular}{lrrrr}
\hline Atom & $\boldsymbol{x}$ & $\boldsymbol{y}$ & $\boldsymbol{z}$ & $\boldsymbol{U}_{\text {iso }}{ }^{*} / \boldsymbol{U}_{\text {eq }}$ \\
\hline H12 & 0.728798 & 0.359978 & -0.046907 & $0.040^{*}$ \\
C13 & $0.7571(5)$ & $0.4526(3)$ & $0.0697(3)$ & $0.0280(9)$ \\
H13 & 0.863475 & 0.476323 & 0.050879 & $0.034^{*}$ \\
\hline
\end{tabular}

\section{Experimental details}

In the structure, all $\mathrm{H}$ atoms were positioned geometrically and refined using a riding model, $\mathrm{C}-\mathrm{H}_{\text {aromatic }}=0.95 \AA$. The $\mathrm{H}$ atom isotropic displacement parameters were fixed; $U_{\text {iso }}(\mathrm{H})=1.2 U_{\text {eq }}(\mathrm{C})$.

\section{Comment}

Rhenium and two of its isotopes, ${ }^{186} \mathrm{Re}$ and ${ }^{188} \mathrm{Re}$, have found use in radiopharmacy as a therapeutic radionuclei. ${ }^{186} \mathrm{Re}$ and ${ }^{188} \mathrm{Re}$ are both beta emitters with half-lifes of 90 and $17 \mathrm{~h}$, respectively. ${ }^{186} \mathrm{Re}$ has beta emission energy of $1.08 \mathrm{MeV}$, and ${ }^{188} \mathrm{Re}$ emits its beta particles with an energy of $2.12 \mathrm{MeV}$ thus allowing for maximum tissue penetration depths of 5 and $11 \mathrm{~mm}$, respectively [7, 8]. These emission properties together with the accessibility achieved from the utilization of the ${ }^{188} \mathrm{~W} /{ }^{188} \mathrm{Re}$ generator, for ${ }^{188} \mathrm{Re}$, and cyclotron availability, for ${ }^{186} \mathrm{Re}$, has made rhenium an ideal candidate in clinical oncology $[9,10]$. Several classes of rhenium based radiopharmaceuticals exists varying from small molecules, colloids, peptides to antibodies, each of which are coordinated or labelled differently with the rhenium metal centre and are distributed in various ways through the body to the potential disease site, whether it is cancer, arthritis, etc. all of which speaks to the versatility of rhenium-based radiopharmaceuticals [11, 12]. Aside from the direct use of the radioactive isotope, the nonradioactive rhenium can be used as a chemical analogue to the short-lived isotope of technetium namely, ${ }^{99 \mathrm{~m}} \mathrm{Tc}$, which is widely used in the medicinal world today [13]. When used in conjunction both rhenium and technetium, if the appropriate isotopes are used, can form part of a theranostic treatment regime [14]. Additionally ${ }^{188} \mathrm{Re}$, when used together with a luminescent probe bound as a ligand system, has been demonstrated to be a potential theranostic agent utilizing the therapeutic nature of the beta particles emitted and diagnostic potential of the luminescent ligand system [15-17].

The crystal structure exhibits the expected distorted octahedral geometry for rhenium-tricarbonyl based systems as indicated by the $\mathrm{N}_{1}-\mathrm{Re}_{1}-\mathrm{N}_{2}$ bond angle of $87.5(1)^{\circ}$.
The $\operatorname{Re}_{1}-C_{1-3}$ bond lengths are typical for rheniumtricarbonyl complexes with an average bond distance of 1.905(7) $\AA$. The nitrato $\mathrm{O}_{4}-\mathrm{Re}_{1}$ bond distance is 2.153(2) $\AA$, and the dihedral angle generated by the planes of the two pyridine ligands is $65.4(1)^{\circ}$. Currently, there are four neutral bis-pyridine based rhenium-tricarbonyl structures known and available in the Cambridge Structural Database (CSD) [18] each varying in what ligand is coordinated in the $6^{\text {th }}$ position on the rhenium metal centre. These are bromido (LODMUN) [19], trifluoromethanesulfonato (PAXLUW) [20], chlorido (PUVHIX) [21] and phenylacetylenyl (VIJWAM) complexes [22]. A pattern of inverse correlation can be observed when comparing the dihedral angle, made by the two planes of the two pyridine ligands, with the $\mathrm{Re}-$ $\mathrm{Br} / \mathrm{Cl} / \mathrm{O} / \mathrm{C}$ bond distance between the five structures. As the bond distance between the metal and $6^{\text {th }}$ ligand increases for VIJWAM $\left(\mathrm{Re}_{1}-\mathrm{C}_{4} 2.108(9) \AA\right)$, this title compound $\left(\mathrm{Re}_{1}-\right.$ $\mathrm{O}_{4}$ 2.153(2) $\AA$ ), PAXLUW $\left(\mathrm{Re}_{1}-\mathrm{O}_{1}\right.$ 2.194(4) $\AA$ ), PUVHIX $\left(\mathrm{Re}_{1}-\right.$ $\mathrm{Cl}_{1}$ 2.447(4) $\AA$ ) and LODMUN $\left(\mathrm{Re}_{1}-\mathrm{Br}_{1} 2.560(2) \AA\right)$; the dihedral angle decreases $\left(69.9(3)^{\circ}, 65.4(1)^{\circ}, 61.8(3)^{\circ}\right.$, $54.3(1)^{\circ}$ and $\left.53.5(1)^{\circ}\right)$. This suggests that the relative position of freely rotating ligands bound equatorially around the metal can be directly affected by changing the $6^{\text {th }}$ axially coordinated ligand (and the bond distance thereof), either by influencing the electron donation ability or the steric influence of the $6^{\text {th }}$ ligand thus providing a means of fine tuning the geometric parameters of a potential radiopharmaceutical.

Author contribution: All the authors have accepted responsibility for the entire content of this submitted manuscript and approved submission.

Research funding: Financial assistance from the University of the Free State (UFS), SASOL, the South African National Research Foundation (SA-NRF) is gratefully acknowledged, part of this material is based on work supported by the SA-NRF (Grant No.: UID 99139).

Conflict of interest statement: The authors declare no conflicts of interest regarding this article.

\section{References}

1. Bruker. APEX3 and SAINT; Bruker AXS Inc.: Madison, WI, USA, 2016.

2. MacRae C. F., Sovago I., Cottrell S. J., Galek P. T. A., McCabe P., Pidcock E., Platings M., Shields G. P., Stevens J. S., Towler M., Wood P. A. Mercury 4.0: from visualization to analysis, design and prediction. J. Appl. Crystallogr. 2020, 53, 226-235.

3. Dolomanov O. V., Bourhis L. J., Gildea R. J., Howard J. A. K., Puschmann H. OLEX2: a complete structure solution, refinement and analysis program. J. Appl. Crystallogr. 2009, 42, 339-341. 
4. Sheldrick G. M. Crystal structure refinement with SHELXL. Acta Crystallogr. 2015, A71, 3-8.

5. Sheldrick G. M. Crystal structure refinement with SHELXL. Acta Crystallogr. 2015, C71, 3-8.

6. Brink A., Visser H. G., Roodt A. Novel imino rhenium (I) tricarbonyl complexes of salicylidene-derived ligands: synthesis, $\mathrm{X}$-ray crystallographic studies, spectroscopic characterization and DFT calculations. Polyhedron 2013, 52, 416-423.

7. Baglin C. M., Berkeley L. Nuclear data sheets for $A=186$. Nucl. Data Sheets 2003, 99, 1-196.

8. Singh B. Nuclear data sheets for $A=188$. Nucl. Data Sheets 2002, 95, 387-542.

9. Alberto R. Application of technetium and rhenium in nuclear medicine. COSMOS 2012, 08, 83-101.

10. Theobald A. E., Theobald T. Sampson's Textbook of Radiopharmacy; Pharmaceutical Press: London, 2011.

11. Lepareur N., Lacoeuille F., Bouvry C., Hindré F., Garcion E., Chérel M., Noiret N., Garin E., Russ Knapp F. F. Rhenium-188 labeled radiopharmaceuticals: current clinical applications in oncology and promising perspectives. Front. Med. 2019, 6, 1-19.

12. Majumder S., Borah B. P., Bhuyan J. Rhenium in the core of porphyrin and rhenium bound to the periphery of porphyrin: synthesis and applications. Dalton Trans. 2020, 49, 8419-8432.

13. Alberto R. From oxo to carbonyl and arene complexes: a journey through technetium chemistry. J. Organomet. Chem. 2018, 869, 264-269.

14. Frei A., Mokolokolo P. P., Bolliger R., Braband H., Tsosane M. S., Brink A., Roodt A., Alberto R. Self-assembled multinuclear complexes incorporating 99mTc. Chem. Eur. J. 2018, 24, 10397-10402.

15. Yang J., Cao Q., Zhang H., Hao L., Zhou D., Gan Z., Li Z., Tong Y. X., Ji L. N., Mao Z. W. Targeted reversal and phosphorescence lifetime imaging of cancer cell metabolism via a theranostic rhenium(I)-DCA conjugate. Biomaterials 2018, 176, 94-105.

16. Stephenson K. A., Banerjee S. R., Besanger T., Sogbein O. O., Levadala M. K., McFarlane N., Lemon J. A., Boreham D. R., Maresca K. P., Brennan J. D., Babich J. W., Zubieta J., Valliant J. F. Bridging the gap between in vitro and in vivo imaging: isostructural Re and $99 \mathrm{mTc}$ complexes for correlating fluorescence and radioimaging studies. J. Am. Chem. Soc. 2004, 126, 8598-8599.

17. Yoshimura T., Nagata K., Shiroyama T., Kino Y., Takayama T., Sekine T., Shinohara A. A luminescent dicyanidonitridotechnetium(v) core with tridentate ligand coordination sites. Dalton Trans. 2018, 47, 16027-16030.

18. Groom C. R., Bruno I. J., Lightfoot M. P., Ward S. C. The Cambridge structural database. Acta Crystallogr. 2016, B72, 171-179.

19. Franklin B. R., Herrick R. S., Ziegler C. J., Çetin A., Barone N., Condon L. R. Reactions of the $\operatorname{Re}(\mathrm{CO})_{3}\left(\mathrm{H}_{2} \mathrm{O}\right)_{3}{ }^{+}$synthon with monodentate ligands under aqueous conditions. Inorg. Chem. 2008, 47, 5902-5909.

20. Ouh L. L., Müller T. E., Yan Y. K. Intramolecular hydroamination of 6-aminohex-1-yne catalyzed by Lewis acidic rhenium(I) carbonyl complexes. J. Organomet. Chem. 2005, 690, 3774-3782.

21. Bélanger S., Hupp J. T., Stern C. L. facTricarbonylchlorobis(pyridine- $N$ )rhenium and factricarbonylchlorobis(4,4'-bipyridine-N)rhenium. Acta Crystallogr. 1998, C54, 1596-1600.

22. Artamkina G. A., Kovalenko S. V., Beletskaya I. P., Reutov O. A. Introduction of a carbon-carbon bond into electron-deficient aromatic compounds. Russ. Chem. Rev. 1990, 59, 750-777. 